\title{
Erratum to: Carbon and Nitrogen Decoupling Under an 11-Year Drought in the Shortgrass Steppe
}

\author{
Sarah E. Evans ${ }^{1 *}$ and Ingrid C. Burke ${ }^{2}$ \\ ${ }^{1}$ Graduate Degree Program in Ecology and Natural Resource Ecology Laboratory, Colorado State University, Fort Collins, \\ Colorado 80523, USA; ${ }^{2}$ Environment and Natural Resources Program, Department of Botany, Department of Ecosystem \\ Science and Management, University of Wyoming, Laramie, Wyoming 82071, USA
}

ERratum to: ECOSYSTEMS

DOI 10.1007/s10021-012-9593-4

In this paper, Figure 7 was published without its Y-axis. A corrected version of the figure is published below. 


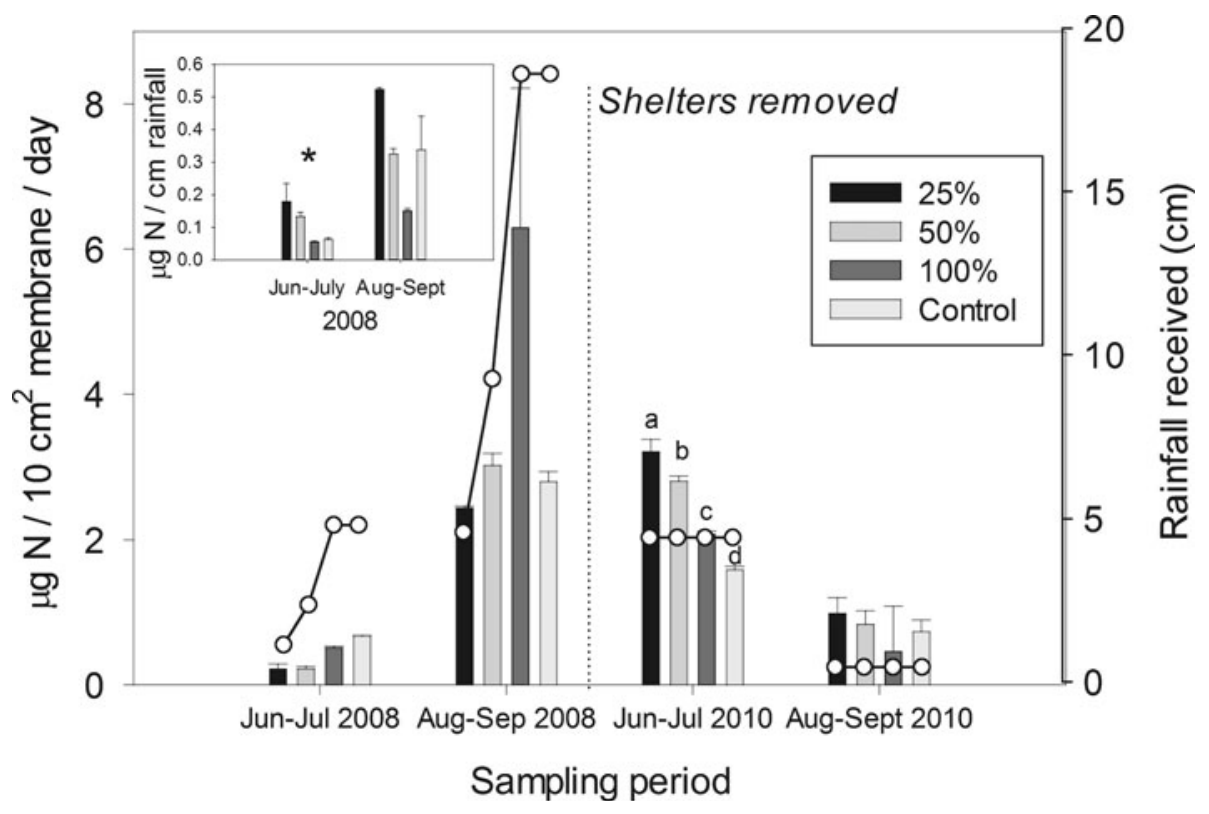

Figure 7. Total inorganic $\mathrm{N}\left(\mathrm{NO}_{3}{ }^{-}-\mathrm{N}+\mathrm{NH}_{4}{ }^{+}-\mathrm{N}\right)$ captured on ion-exchange membrane probes in the 10 th year of a longterm drought manipulation in the shortgrass steppe (2008), when rainfall the plots received varied (shown by open dots) and the first year of recovery (2010), when all plots received the same amount of rainfall. Bars show $\mu$ g-N accumulated per $10 \mathrm{~cm}$ probe per day in each 2-month period of burial, whereas inset shows $\mu \mathrm{g}-\mathrm{N}$ per cm rainfall during 2008 , when treatments received unequal rainfall. Where significant differences among treatments occurred, significant pairwise differences $(P<0.05)$ are indicated by letters. Ratios of nitrate to ammonium were consistent across treatments within any given time point, so are not shown separately. 